\section{穴 Heighten Science \\ P U B L I C I T I O N S Corporation ISSN 2577-1469}

*Address for Correspondence: Christine Skerka, Department of Infection Biology, Leibniz Institute for Natural Product Research and Infection Biology, Beutenbergstr 11a, 07745 Jena, Germany,

Email: Christine.Skerka@hki-jena.de

Submitted: 18 September 2017

Approved: 20 September 2017

Published: 21 September 2017

Copyright: @2017 Lin Y, et al. This is an open access article distributed under the Creative Commons Attribution License, which permits unrestricted use, distribution, and reproduction in any medium, provided the original work is properly cited

Check for updates

\title{
Nicotinamide as a treatment option of Age-Related Macular Degeneration
}

\author{
Yuchen Lin ${ }^{1}$, Peter F. Zipfel ${ }^{1,2}$ and Christine Skerka ${ }^{1 *}$ \\ 'Department of Infection Biology, Leibniz Institute for Natural Product Research and Infection \\ Biology, Beutenbergstr 11a, 07745 Jena, Germany \\ ${ }^{2}$ Friedrich Schiller University Jena, Germany
}

Age related macular degeneration is a severe disease of mainly elderly people and leads to central vision loss because of the degeneration of the retinal pigment epithelium [1]. Genetic and environmental factors are responsible for the accumulation of extracellular material and deposit formation near the retinal pigment epithelial (RPE) layer, which leads to loss of photoreceptors and induction of chronic inflammation. The deposits are composed of lipids and proteins including many complement proteins, indicating the involvement of the complement system in the degenerative process and chronic inflammation [2]. So far there is no treatment for the dry form of AMD, except nutritional supplementation with antioxidants and vitamins [3]. Combined with a prolonged lifetime expectation in developed countries, AMD is developing to a social and economic burden. Therefore, there is an urgent need for a treatment of AMD that can delay disease manifestation and progression for several years.

In a recent manuscript, Saini and colleagues analyzed a vitamin B derivate, nicotinamide (NAM), as a potential treatment strategy of AMD [4]. The antiinflammatory activity of NAM is not entirely new and may have inspired the investigators to look in detail at the effect of this drug for AMD treatment. In 2008, Temple and her group reported about the treatment of $3 \times \mathrm{Tg}-\mathrm{AD}$ mice, a mouse model for Alzheimer's disease (AD), with NAM. Their work suggested that NAM treatment selectively reduces a phosphorylated species of tau associated with microtubule depolymerization and implicated in AD. Treatment of mice restored cognitive decline related to AD pathology indicate a readily available therapeutic for the treatment [5]. Collectively NAM was identified as a cytoprotectant that blocks cellular inflammatory cell activation, early apoptotic phosphatidylserine exposure, and late nuclear DNA degradation [6]. Therefore, NAM supplementation was suggested for the treatment of chronic diseases with an immune system dysfunction as seen in diabetes and agerelated diseases.

Sinai et al. [4], investigated the effects of NAM in a human induced pluripotent stem cell (iPSC) model of AMD which they they previously established. The advantage of this model is evident. The investigators used cells from AMD patients with or without a specific ARMS2/HTRA1 risks haplotype as well as from control people to generate iPSCs and to compare the effects of NAM. The authors showed that iPSC cells express a broad panel of drusen like deposits and AMD associated molecules. Also, iPSC-RPE from all AMD patients studied, demonstrated an increased expression of inflammatory and complement factors as compared to controls. The expression of complement genes C3 and CFI was significantly enhanced in patient cell lines carrying the homozygous 
ARMS2/HTRA1 risk alleles. Interestingly, the expression of the classical complement components $\mathrm{C} 1 \mathrm{~s}$ and $\mathrm{C} 1 \mathrm{r}$ was enhanced in AMD derived iPSC-RPE, thus indicating a role of the classical pathway in AMD.

To determine the effect of NAM on the iPSC-RPE, the authors used a large panel of methods (ELISA, transcriptome analysis, qPCR) for analysis. Overall, the results revealed similar responses to NAM of all generated iPSC-RPEs, with enhanced inhibition of several markers including, drusen components ApoE,ApoJ, and VEGF in AMD lines. Furthermore, NAM inhibited transcription of complement and inflammatory factors. Moreover, NAM increased RPE survival by targeting aging-associated pathways.

Given the strong involvement of complement in AMD (genetic association [7], complement proteins in drusen [4,8,9], ARMS2 protein function in complement [10], fctor $\mathrm{H}$ on microglial [11] and the dramatic reduction of C3 expression levels in iPSCRPE lines upon NAM treatment, justified the question by the investigators whether the NAM effect was largely explained by the reduction of C3 transcription. To answer this question, the authors inhibited C3 expression in their iPSC cell models via shRNA. This treatment inhibited C5 transcription, but in contrast to NAM treatment, they did not observe any effects on complement regulator $\mathrm{CFH}$ expression or factor I (CFI) (Figure 1). Silencing of C3 expression also did not increase cell viability as seen with NAM. This is likely explained by intracellular C3 functions which were reported to be involved in signal transduction pathways directing survival, repair, and regeneration [12,13]. Based on these results the authors concluded that $\mathrm{C} 3$ inhibition does not have the multiple beneficial effects like NAM.

However, although C3 inhibition does not have a similar suppressive effect on gene transcription like NAM, the subsequent inhibition of C5 expression might have a specific impact on complement mediated inflammatory responses of microglia cells attraction and activation of blood monocytes, which was not tested here. Although NAM holds great potential for multiple disease entities, there are also sounds of caution based on complex biological roles NAM plays in cell survival pathways and unwanted detrimental effects in cellular proliferation that leads to cancer [14]. Clinical trials with NAM will clarify whether this readily available promising substance fulfills the expectations to reduce inflammation and damage in AMD patients.
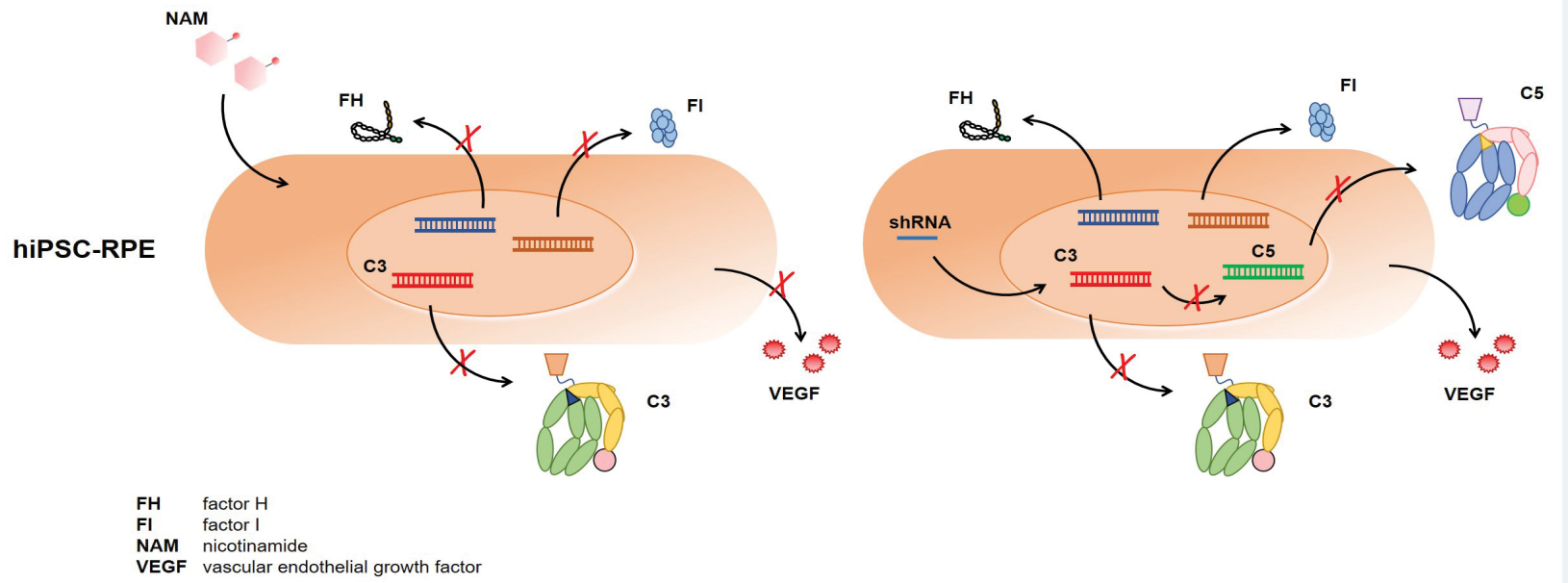

VEGF vascular endothelial growth factor

Figure 1: NAM-effect on complement in iPSC-RPE cells.

Treatment of iPSC-RPE cells with NAM inhibits more complement genes compared to C3-silenced cells. Furthermore VEGF secretion is reduced in NAM treated RPE cells, but not in C3 -gene silenced RPE cells. 


\section{Acknowledgement}

The work was supported by the Deutsche Forschungsgemeinschaft (Sk46/2-2).

Yuchen Lin is a doctoral scientist of the graduate school 'International Leibniz Research School for Microbial and Biomolecular Interactions'.

\section{References}

1. Whitmore SS, Sohn EH, Chirco KR, Drack AV, Stone EM, et al. Complement activation and choriocapillaris loss in early AMD: implications for pathophysiology and therapy. Prog Retin Eye Res. 2015; 45: 1-29. Ref.: https://goo.gl/84HxeU

2. Hollyfield JG, Salomon RG, Crabb JW. Proteomic approaches to understanding age-related macular degeneration. Adv Exp Med Biol. 2003; 533: 83-89. Ref.: https://goo.gl/cTzE5Q

3. Al-Zamil WM, Yassin SA. Recent developments in age-related macular degeneration: a review. Clin Interv Aging. 2017; 12: 1313-1330. Ref.: https://goo.gl/UeZCz6

4. Saini JS, Corneo B, Miller JD, Kiehl TR, Wang Q, et al. Nicotinamide Ameliorates Disease Phenotypes in a Human iPSC Model of Age-Related Macular Degeneration. Cell Stem Cell. 2017; 20: 635-647. Ref.: https://goo.gl/rUuJCm

5. Green KN, Steffan JS, Martinez-Coria H, Sun X, Schreiber SS, et al. Nicotinamide restores cognition in Alzheimer's disease transgenic mice via a mechanism involving sirtuin inhibition and selective reduction of Thr231-phosphotau. J Neurosci. 2008; 28: 11500-11510. Ref.: https://goo.gl/kH7jna

6. Maiese K, Chong ZZ, Hou J, Shang YC. The vitamin nicotinamide: translating nutrition into clinical care. Molecules. 2009; 14: 3446-3485. Ref.: https://goo.gl/uAYMfT

7. Fritsche LG, IgI W, Bailey JN, Grassmann F, Sengupta S, et al. A large genome-wide association study of age-related macular degeneration highlights contributions of rare and common variants. Nat Genet. 2016; 48: 134-143. Ref.: https://goo.gl/9mywt3

8. Wang L, Clark ME, Crossman DK, Kojima K, Messinger JD, et al. Abundant lipid and protein components of drusen. PLoS One. 2010; 5: 10329. Ref.: https://goo.gl/oa36ye

9. Hollyfield JG, Salomon RG, Crabb JW. Proteomic approaches to understanding age-related macular degeneration. Adv Exp Med Biol. 2003; 533: 83-89. Ref.: https://goo.gl/ohJxsj

10. Micklisch S, Lin Y, Jacob S, Karlstetter M, Dannhausen K, et al. Age-related macular degeneration associated polymorphism rs10490924 in ARMS2 results in deficiency of a complement activator. J Neuroinflammation. 2017; 14: 4. Ref.: https://goo.gl/yzbfzx

11. Calippe B, Augustin S, Beguier F, Charles-Messance H, Poupel L, et al. Complement Factor H Inhibits CD47-Mediated Resolution of Inflammation. Immunity. 2017; 46: 261-272. Ref.: https://goo.gl/ke5hWL

12. Liszewski MK, Kolev M, Le Friec G, Leung M, Bertram PG, et al. Intracellular complement activation sustains $T$ cell homeostasis and mediates effector differentiation. Immunity. 2013; 39: 1143-1157. Ref.: https://goo.gl/WrEScT

13. Hawksworth OA, Coulthard LG, Woodruff TM. Complement in the fundamental processes of the cell. Mol Immunol. 2017; 84: 17-25. Ref.: https://goo.gl/68gxE3

14. Maiese $K$, Chong ZZ, Hou J, Shang YC. The vitamin nicotinamide: translating nutrition into clinical care. Molecules. 2009; 14: 3446-3485. Ref.: https://goo.gl/6UVF48 